\title{
Skeletal myogenesis by human embryonic stem cells
}

\author{
Jun Ke Zheng ${ }^{1}$, Yi Wang ${ }^{1}$, Aditi Karandikar ${ }^{1}$, Qian Wang ${ }^{1}$, Hui Gai ${ }^{1}$, Ai Lian Liu ${ }^{1}$, Chao Peng ${ }^{1}$, \\ Hui Zhen Sheng ${ }^{1,2}$ \\ ${ }^{1}$ Center for Developmental Biology, Xinhua Hospital, School of Medicine, Shanghai Jiao Tong University, 1665 Kong Jiang Road, \\ Shanghai 200092, China; ${ }^{2}$ Laboratory of Stem Cell Biology, Institute of Biochemistry and Cell Biology, Shanghai Institutes of Bio- \\ logical Sciences, Chinese Academy of Sciences, Shanghai 200031, China
}

We have examined the myogenic potential of human embryonic stem (hES) cells in a xeno-transplantation animal model. Here we show that precursors differentiated from hES cells can undergo myogenesis in an adult environment and give rise to a range of cell types in the myogenic lineage. This study provides direct evidences that hES cells can regenerate both muscle and satellite cells in vivo and are another promising cell type for treating muscle degenerative disorders in addition to other myogenic cell types.

Cell Research (2006) 16:713-722. doi:10.1038/sj.cr.7310080; published online 20 June 2006

Keywords: Skeletal myogenesis, embryonic stem cell, differentiation

\section{Introduction}

Skeletal muscles have the ability to grow in response to workload or to repair themselves in case of muscle injury. Post-natal growth, repair, and maintenance of muscle fibers are based on a population of mononucleated muscle stem cells called satellite cells [1], which are located beneath the basal membrane of muscle fibers. Satellite cells function as tissue-specific precursor cells responsible for the regeneration of skeletal muscles. A decrease in the number and/or function of satellite cells may lead to degenerative disorders [2], such as Duchenne muscular dystrophy. A proposed therapy for these disorders is myogenic cell transfer [3]. Both satellite cells and myoblasts, especially those from Duchenne's muscular dystrophy patients, have a limited proliferation potential [4]. Results from clinical trials have shown that very few myoblasts survive transfer [5].

In addition to satellite cells, other progenitor cells capable of myogenesis have been identified. Progenitor cells isolated from the dorsal aorta of mouse embryos

Correspondence: Hui Zhen Sheng

Tel/Fax: +86-21-55570017;

E-mail: hzsheng2003@yahoo.com

Received 27 Jan 2006; revised 11 May 2006; accepted 26 May 2006; published online 20 June 2006 can generate myogenic clones in vitro [6]. Those derived from bone marrow can participate in the regeneration of the damaged skeletal muscle [7,8]. Side population cells isolated from the bone marrow and skeletal muscle can incorporate into muscle and partially restore the dystrophin expression in the $m d x$ mice $[9,10]$. Remarkably, side population cells isolated from muscles, when transplanted via the tail vein, can travel through the capillaries and enter damaged muscles in $m d x$ mice [11]. Human adult stem cells, for example, the circulating AC133+ stem cells and adult human synovial membrane-derived mesenchymal stem cells, can also restore dystrophin expression and ameliorate function in the mouse model for degenerative muscle disorders $[12,13]$.

Human embryonic stem (hES) cells have the potential to differentiate into all cell types of the body [14], including those of the myogenic lineage. Once an optimal protocol is established to direct the differentiation of hES cells to appropriate muscle precursors, hES cells can become an unlimited cell source for treating degenerative muscle disorders. Toward such a goal, we have established a mouse model for testing the myogenic potential of precursor cells. Using this model, we show that precursor cells derived from $\mathrm{hES}$ cells can incorporate effectively into the mouse muscle and differentiate to a range of cell types in the myogenic lineage, including satellite cells. 
A

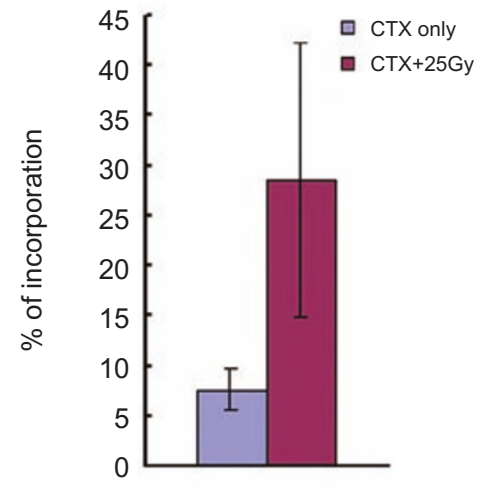

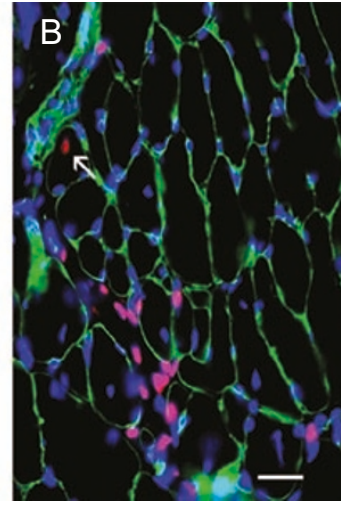

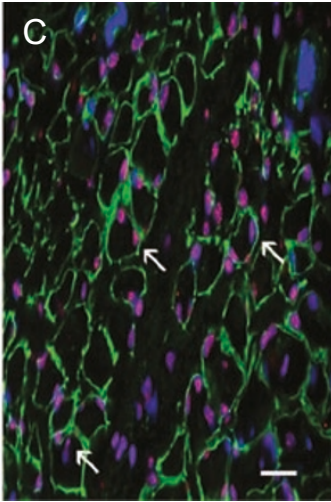

Figure 1 Irradiation after cardiotoxin treatment improved the incorporation of hES cell-derived precursors into TA muscles in NOD/SCID mice. (A) Percentages of regenerated myofibers containing human nuclei in TA muscles preconditioned either by cardiotoxin alone or in combination with irradiation at $25 \mathrm{~Gy}(P<0.01)$. See details in Materials and Methods $(\mathbf{B}, \mathbf{C})$. Representative fields from TA muscles preconditioned either with cardiotoxin alone (B) or in combination with irradiation $(\mathbf{C})$. Arrows in (B) and (C) showed the human nuclei beneath the laminin. Sections in (B) and (C) were incubated with antibodies against human-specific NuMA antigen (red) and laminin (green). Nuclei were highlighted by staining with Hoechst 33342 (blue). These experiments were performed using the SH39 line. Scale bar $=25 \mu \mathrm{m}$.

\section{Materials and Methods}

\section{Myogenic differentiation in culture}

Two hES cell lines, H1 [14] (WiCell Research Institute, WI, USA, passages 40-60) and SH39 (derived by the Center for Developmental Biology, Xinhua Hospital, Shanghai, China, passages 30-40), were maintained on irradiated mouse feeders in 79\% DMEM/F-12 supplemented with $20 \%$ knockout serum replacement, $2 \mathrm{mM}$ L-glutamine, $1 \%$ MEM nonessential amino acid solution, $0.1 \mathrm{mM} \beta$-mercaptoethanol, and $4 \mathrm{ng} / \mathrm{ml} \mathrm{bFGF} \mathrm{(all} \mathrm{from} \mathrm{Gibco/Invitrogen} \mathrm{BRL).}$

Embryoid bodies (EBs) were formed in suspension in DMEM, supplemented with $10 \%$ fetal bovine serum (Hyclone, FBS), $0.1 \mathrm{mM}$ $\beta$-mercaptoethanol, $2 \mathrm{mM}$ glutamine, and 1\% MEM nonessential amino acid solution [15]. After 4-6 days, EBs were transferred to $0.1 \%$ gelatin-coated tissue culture dishes. Once attached, the cultures were switched to one of the three differentiation media. Medium A is composed of DMEM, $10 \%$ FBS, $1 \times 10^{-8} \mathrm{M}$ dexamethasone (Sigma), $1 \times$ insulin-transferrin-seleium (Gibco BRL), 2 mM glutamine, and 10 $\mathrm{ng} / \mathrm{ml} \mathrm{EGF} \mathrm{(Sigma).} \mathrm{Medium} \mathrm{B} \mathrm{is} \mathrm{composed} \mathrm{of} \mathrm{DMEM,} \mathrm{2 \%} \mathrm{horse}$ serum, and $2 \mathrm{mM}$ glutamine. Medium $\mathrm{C}$ is composed of DMEM, $10 \%$ FBS, $10 \%$ horse serum (Sigma), and $2 \mathrm{mM}$ glutamine. Cells were split into subcultures when they reached confluence. In some experiments, $10 \mathrm{mM}$ 5-azacytidine (Sigma) was added to Medium $\mathrm{C}$ for $24 \mathrm{~h}$ to promote myogenesis. Marker expression was analyzed 2 or 4 weeks after EB plating or 5-azacytidine treatment. A murine myoblast line (ATCC CRL-1447, G-7) was cultured with Medium $\mathrm{C}$ and was used as a positive control for antibody staining. To determine the number of cells expressing muscle markers in culture, approximately 300 cells from 10 fields were counted.

\section{Establishing the mouse model for myogenesis}

All pretransplantation studies were performed on C57BL/6 mice (from the Center for Experimental Animals, Chinese Academy of
Science). Animal procedures were carried out in accordance with the guidelines of the Shanghai Second Medical University. Cardiotoxin from Naja mossambica mossambica (Sigma, $1 \mathrm{mg} / \mathrm{ml}$ in PBS, $20 \mu 1$ per mouse) was injected into the tibialis anterior (TA) muscles of the right hindlimbs of 6- to 10 -week-old mice. The left hindlimb of the mouse served as a control. Two mice were killed by cervical dislocation for each time point after cardiotoxin injection. TA muscles were removed and fixed in 4\% paraformaldehyde. Paraffin sections were stained with hematoxylin and eosin for histological examination. In other cases, hindlimbs of the mice were irradiated at 18 or $25 \mathrm{~Gy}$ after injection with cardiotoxin using a Varian $2100 \mathrm{C} / \mathrm{D}$ Linear Accelerator with a photon energy of $10 \mathrm{MV}$. One week after irradiation, TA muscles were collected for pathological examination.

\section{Cell transplantation}

TA muscles of 8-week-old NOD-SCID mice were injected with $20 \mu \mathrm{l}(1 \mathrm{mg} / \mathrm{ml})$ of cardiotoxin. Twenty-four hours later, the mice received $25 \mathrm{~Gy} \mathrm{X}$-radiation delivered to the hindlimbs. For transplantation, $1 \times 10^{6}$ myogenic cells derived from hES cells in $20 \mu 1$ of PBS $+2 \%$ FBS were injected into TA muscles $24 \mathrm{~h}$ after irradiation.

\section{Irradiation dosage and time course analysis}

To determine the optimal dose of irradiation, 8-week-old NODSCID mice were treated with either $20 \mu \mathrm{g}$ of cardiotoxin alone or in combination with different doses of irradiation $(18,25$, or $50 \mathrm{~Gy})$. Myogenic cells $\left(1 \times 10^{6}\right)$ derived from hES cells were transplanted to TA muscles $24 \mathrm{~h}$ after irradiation. For the time course, 8 -week-old NOD-SCID mice were treated with $20 \mu \mathrm{g}$ of cardiotoxin followed by irradiation ( $25 \mathrm{~Gy}) 24 \mathrm{~h}$ later. Cells were transplanted 0,24 , or $48 \mathrm{~h}$ after irradiation. Two weeks after transplantation, the muscle was collected and sectioned. To determine incorporation efficiencies, muscle sections were double-stained with antibodies against laminin and anti-human nuclear mitotic apparatus protein (NuMA). Sections 
Table 1 Incorporation efficiency is influenced by the duration between irradiation and transplantation

\begin{tabular}{cccc}
\hline $\begin{array}{l}\text { Time after } \\
\text { irradiation } \\
\text { (h) }\end{array}$ & $\begin{array}{l}\text { Number of } \\
\text { myofiber } \\
\text { counted }(n)\end{array}$ & $\begin{array}{l}\text { Number of } \\
\text { hybrid } \\
\text { myofibers }\end{array}$ & $\begin{array}{l}\text { Hybrid } \\
\text { myofiber/total } \\
\text { myofibers (\%) }\end{array}$ \\
\hline 0 & 254 & 25 & 9.84 \\
0 & 471 & 33 & 7.01 \\
24 & 242 & 109 & 45.04 \\
24 & 185 & 45 & 24.32 \\
48 & 372 & 176 & 47.31 \\
48 & 575 & 135 & 23.48 \\
\hline
\end{tabular}

were counter-stained with Hoechst 33342 to highlight nuclei. Approximately 200-500 myofibers in more than 10 fields were counted to calculate the percentage of hybrid myofibers using the following formula: $\%=$ (number of myofibers containing human nuclei/number of total myofibers at transplantation site $) \times 100$. Data from more than three transplantation sites were pooled to calculate mean \pm S.D. (Figure 1). For the time course study, two mice at each time point were subjected to the same analysis and the results were summarized in Table 1. Statistical analyses were performed using the $\chi^{2}$ test.

\section{Tissue collection and analysis}

TA muscles were collected 2-16 weeks after the transplantation, cryoprotected in 30\% sucrose in PBS overnight, embedded in OCT, frozen at $-70{ }^{\circ} \mathrm{C}$ for $1 \mathrm{~h}$, and sectioned. Tissue sections were fixed with chilled acetone for $10 \mathrm{~min}$ at $4{ }^{\circ} \mathrm{C}$. Progenies of hES cells were identified by an NuMA antibody (Oncogen) or a probe against primate-specific Alu repeats (see below).

\section{Immunohistochemistry}

Cells $\left(1 \times 10^{5}\right)$ were grown on coverslips in 24 -well plates and fixed in $4 \%$ paraformaldehyde. For immunofluorescent staining, cells or cryosections were incubated with blocking buffer (3\% BSA in PBS) for $15 \mathrm{~min}$ and then primary antibodies overnight. The antibodies used were against MyoD1, myoglobin (Dako), desmin, troponin I, dystrophin, Myf5, c-Met, muscle cadherin (M-cadherin), neural cell adhesion molecules (NCAM), myosin heavy chains (MHC) (Santa Cruz), $\alpha$-actinin (sacromeric, Sigma), Pax3, Pax 7 (R\&D), laminin (Sigma), and human-specific dystrophin (Chemicon). All antibodies used have been shown to react specifically to the appropriate antigens and were further verified by controls included in each experiment. Fluorescent-conjugated secondary antibodies (Cy3 or FITC) against mouse, rabbit, or goat were obtained from Jackson Laboratory. After counterstaining with Hoechst 33342 (Sigma), samples were mounted using 50\% glycerol in PBS and analyzed by Olympus microscopy equipped with Spot digital camera and software.

To analyze the position of satellite cells, two consecutive muscle sections were laid onto the slide with the common cutting surfaces facing up. After antibody staining, mirror images were collected from the paired sections and analyzed.

\section{In situ hybridization (ISH) with digoxigenin-labeled Alu DNA probes}

DNA-DNA ISH was performed as described previously [16]. In brief, cryosections were dehydrated in alcohol and incubated in a hy-
C-Met
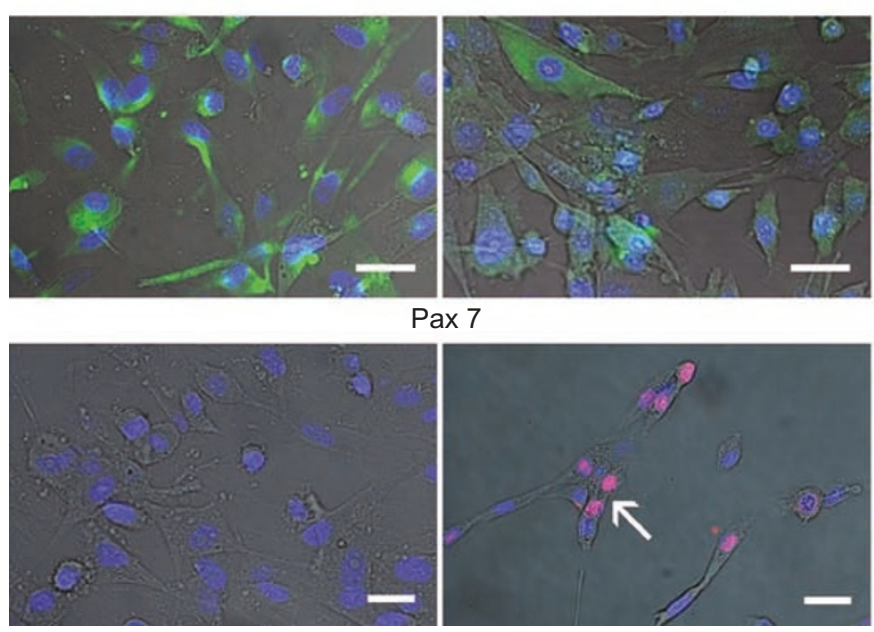

MyoD
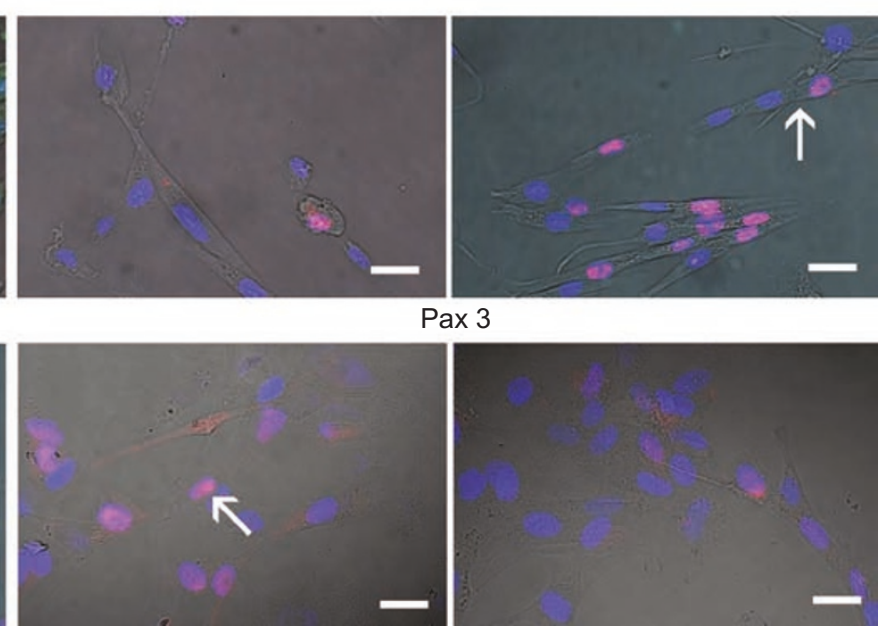

Figure 2 Myogenic differentiation in culture. Before 5-azacytidine treatment (left panels in each pairs), most cells expressed c-Met (green), while a relatively small population in the culture expressed myo D and Pax3 (red nuclei, arrows). Pax7 (red nuclei, arrow) was not expressed. After treatment with 5-azacytidine (right panels), c-Met expression reduced significantly and Pax3 reduced slightly. MyoD and Pax7 expression increased. Following immunofluorescent staining, cells were counterstained with Hoechst 33342 (blue). Both the H1 and SH39 lines were tested for myogenic differentiation in culture. Scale bars $=25 \mu \mathrm{m}$. 
Table 2 Expression of myogenic markers by cells under different culture conditions

\begin{tabular}{|c|c|c|c|c|c|c|}
\hline Antibody & $\begin{array}{l}\text { Myoblast } \\
\text { line (C) (\%) }\end{array}$ & $\begin{array}{l}\mathrm{hES}+10 \% \\
\mathrm{FBS}+\mathrm{EGF}(\mathrm{A}) \\
(2 \mathrm{w})(\%)\end{array}$ & $\begin{array}{l}\text { hES }+2 \% \text { HS } \\
\text { (B) }(2 \mathrm{w})(\%)\end{array}$ & $\begin{array}{l}\mathrm{hES}+10 \% \\
\mathrm{FBS}+10 \% \mathrm{HS}+ \\
5-\mathrm{Aza}(\mathrm{C})(2 \mathrm{w}) \\
(\%)\end{array}$ & $\begin{array}{l}\text { hES+10\% } \\
\text { FBS+EGF(A) } \\
(4 w)(\%)\end{array}$ & $\begin{array}{l}\text { hES }+10 \% \\
\text { FBS }+10 \% \\
\text { HS }+5-\text { Aza }(C) \\
(4 w)(\%)\end{array}$ \\
\hline c-Met & ND & $71.53 \pm 11.07$ & $57.75 \pm 6.03$ & $46.09 \pm 10.90$ & $90.43 \pm 1.80$ & $45.78 \pm 8.45$ \\
\hline Pax7 & $86.95 \pm 4.58$ & ND & ND & $6.31 \pm 3.33$ & ND & $49.24 \pm 9.78$ \\
\hline Desmin & $6.72 \pm 2.57$ & ND & ND & ND & ND & ND \\
\hline $\mathrm{MHC}$ & $4.82 \pm 2.21$ & ND & ND & ND & ND & ND \\
\hline
\end{tabular}

5-Aza = 5-azacytidine; $\mathrm{w}=$ weeks in the differentiation culture. See Materials and Methods; ND=not detected.

A, B, C: The type of medium used. For compositions, see Materials and Methods.

bridization cocktail ( $10 \mu \mathrm{l}$ of $50 \times$ Denhardt's solution, $50 \mu 1$ of $50 \%$ dextran sulfate, $100 \mu \mathrm{l}$ of $20 \times \mathrm{SSC}, 500 \mathrm{ng}$ digoxigenin-labeled Alu probe in $50 \mu \mathrm{l}$ Tris/EDTA buffer, $250 \mu \mathrm{l}$ formamide, and distilled water to make a total volume of $500 \mu \mathrm{l})$. Slides with cryosections were kept in a humidified chamber at $80^{\circ} \mathrm{C}$ for $10 \mathrm{~min}$, cooled on ice for $5 \mathrm{~min}$, incubated at $42^{\circ} \mathrm{C}$ for $3 \mathrm{~h}$, and washed in succession with $2 \times \mathrm{SSC}$, $0.1 \times \mathrm{SSC}$, buffer $1(0.1 \mathrm{M}$ maleic acid, $0.15 \mathrm{M} \mathrm{NaCl}, \mathrm{pH} 7.5)$, and $0.5 \%$ blocking reagent (Roche). After incubation with anti-digoxigenin antibody conjugated with alkaline phosphatase (Roche), color was developed by incubation with nitroblue tetrazolium/5-bromo4-chloro-3-indolyl phosphate (Roche).

\section{Results}

To initiate differentiation, EBs were formed from hES cells using an established protocol [15]. Cells differentiated from EBs were cultured in one of the three media to induce myogenic differentiation. Some of the cultures were treated with 5-azacytidine for $24 \mathrm{~h}$. Marker expression was analyzed 2 or 4 weeks after plating the EBs (see Materials and Methods). 5-Azacytidine treatment caused the cells to decrease in the proliferation rate and became elongated. Many of them arranged themselves in parallel. Results from antibody staining showed that 5 -azacytidine treatment had differential effects on the expression of myogenic genes.
c-Met expression, detected in the majority of the cells in cultures, decreased after the treatment. Pax 3 was expressed by approximately $24 \%$ of the cells in the culture and decreased to about $17 \%$ after the treatment. Treatment of the cultures with 5-azacytidine increased the expression of Pax 7 and MyoD. In addition to treatment by 5 -azacytidine, expression of myogenic markers, including c-Met, Pax 7, and $\mathrm{MyoD}$, was also influenced by the duration in the differentiation media. Expression of the three genes was detected in significantly higher percentages of cells in the 4-week cultures than in the 2-week cultures (Figure 2 and Table 2). In all the culture conditions tested, cells did not express myf5, desmin, dystrophin, MHC, troponin I, M-cadherin, or NCAM, nor did they form myotube or myofiber (data not shown). As c-Met is a marker expressed in very early myogenic precursors and expression of MyoD and Myf5 indicates muscle fate determination $[17,18]$, these results suggest that a large proportion of cells in cultures had the potential, but were not yet determined to the muscle fate (Figure 2 and Table 2). To investigate further the muscle differentiation potential of hES cells, we transplanted precursor cells that had been cultured in Medium A for 4 weeks without 5-azacytidine treatment, into preconditioned TA muscles of NOD-SCID mice.

Figure 3 (A) Inhibition of endogenous proliferation by irradiation. Muscle regeneration in C57BL/6 mice preconditioned with cardiotoxin alone or in combination with irradiation. Degeneration was seen $4 \mathrm{~h}$ after cardiotoxin delivery, and became most apparent in 3 days. Damaged muscles were largely restored in 5-7 days. Irradiation at 18 Gy (mildly) and at 25 Gy (severely) inhibited muscle regeneration. Numerous blue nuclei in the sections are of the cells from inflammatory infiltration. Scale bar $=50 \mu \mathrm{m}$. (B) Myogenic differentiation in vivo. Human nuclei were identified either by the anti-NuMA antibody (red) or by the probe against Alu repeats (purple). Most sections were counterstained with Hoechst 33342 (blue). Expression of c-Met, desmin, MHC (green), and $\alpha$-actinin in mononucleated myoblasts (arrows) was seen. Myofibrils were highlighted by an anti- $\alpha$-actinin antibody (arrowheads). Images were selected from experiments using both the H1 and SH39 lines. Scale bars $=25 \mu \mathrm{m}$. 
A

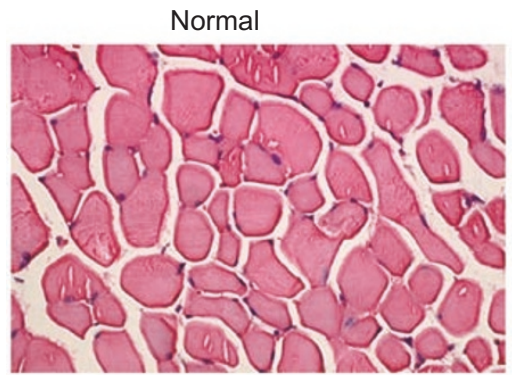

Cardiotoxin 2d
Cardiotoxin $4 \mathrm{~h}$

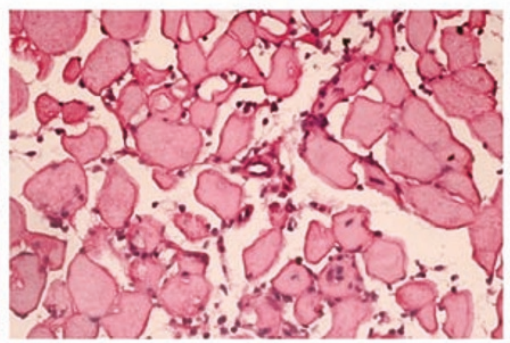

Cardiotoxin $3 d$

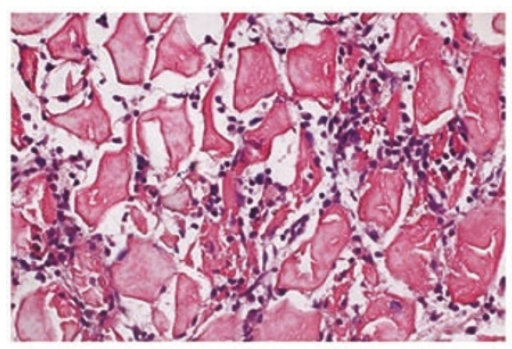

Cardiotoxin $5 d$

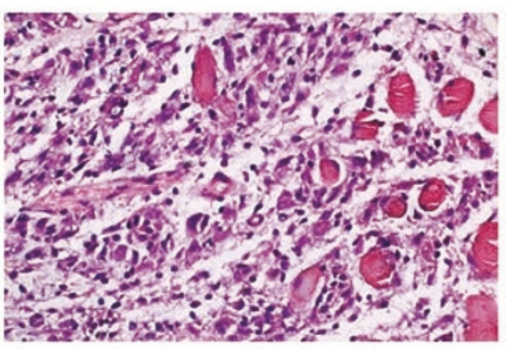

Cardiotoxin 7d

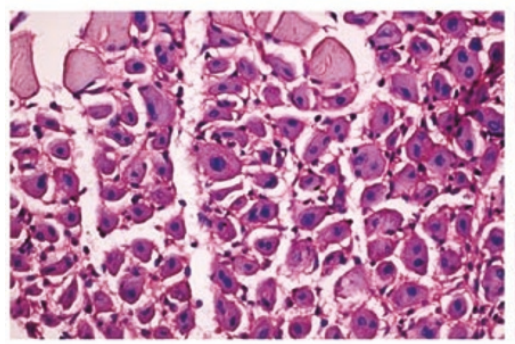
Cardiotoxin+18Gy $7 d$

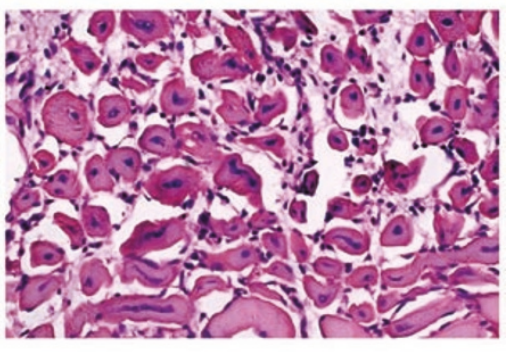

Cardiotoxin+25Gy $7 d$
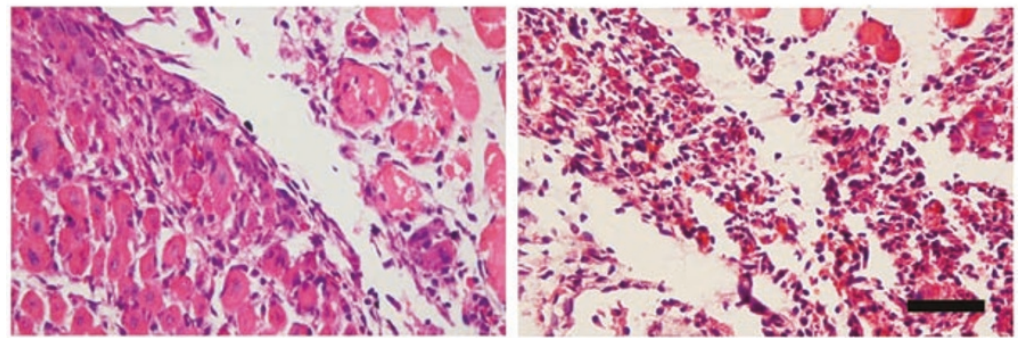

B

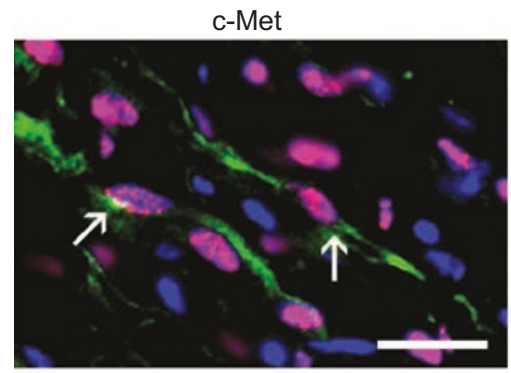

$\alpha$-actinin

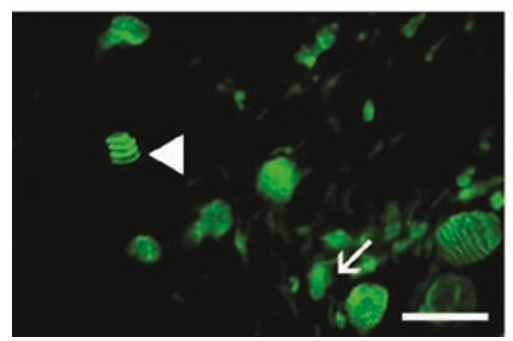

Desmin

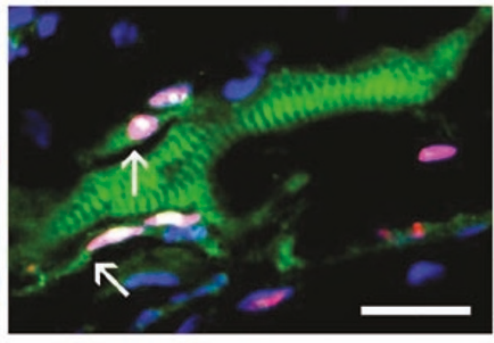

Alu

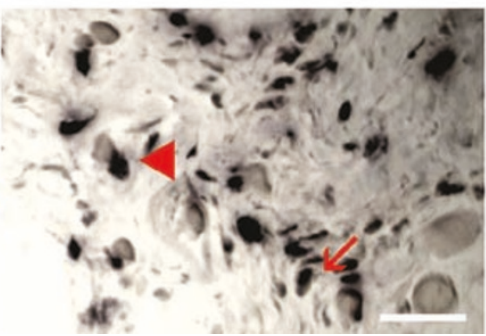

$\mathrm{MHC}$

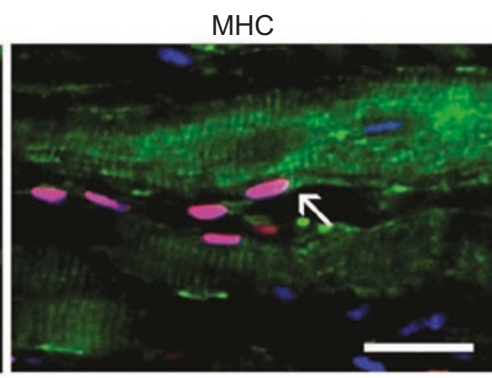

$\alpha$-actinin+Alu

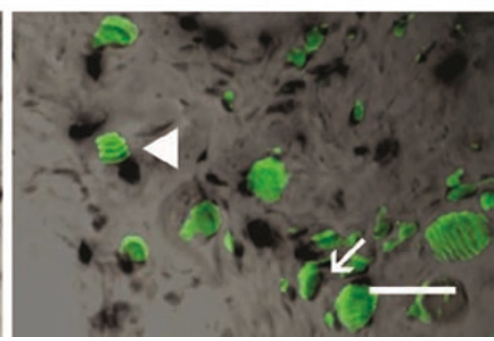

www.cell-research.com | Cell Research 
C

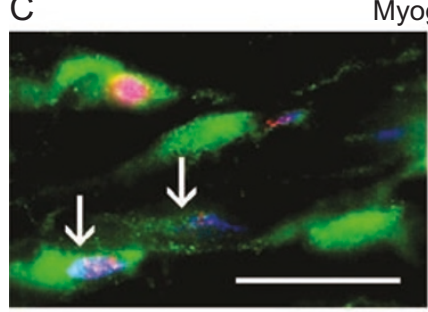

Newly formed myotubes

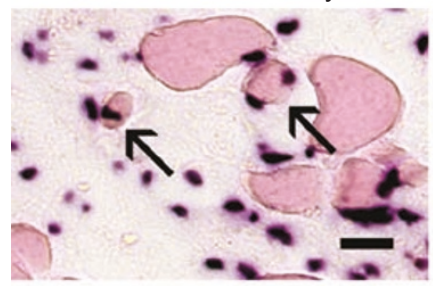

Alu

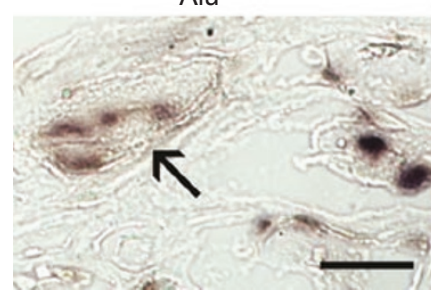

Myoglobin
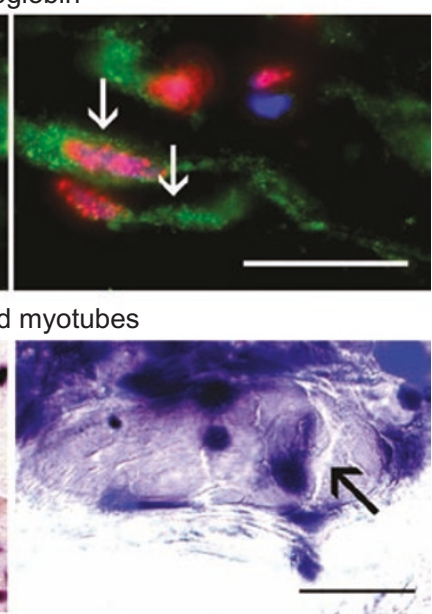

$\alpha$-actinin

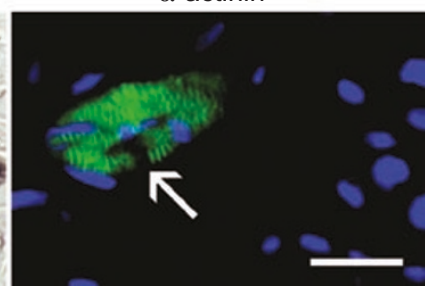

D

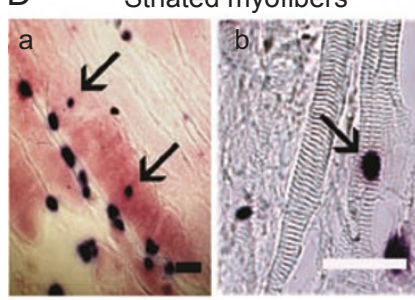

Alu

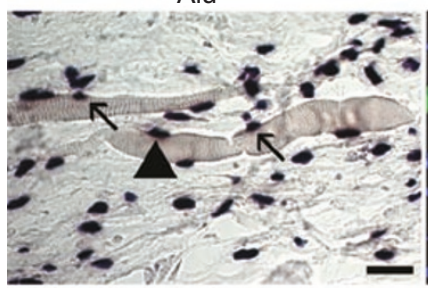

Troponin I

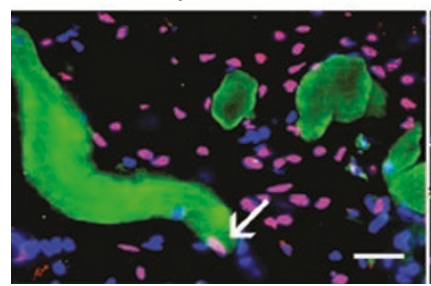

Desmin

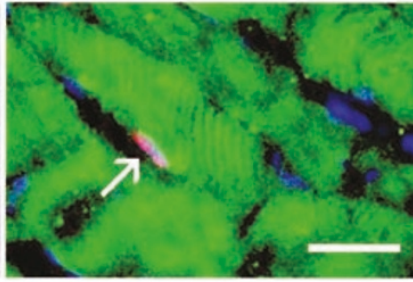

$\alpha$-actinin

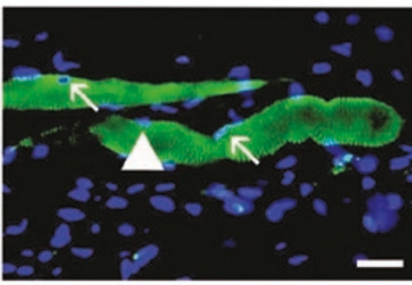

Dystrophin

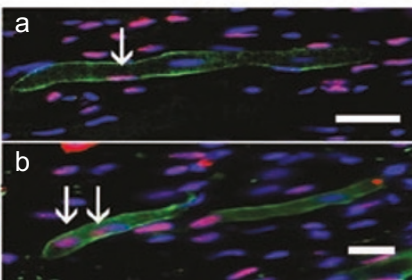

Figure 3 (C) Myogenic differentiation in vivo. Myoblasts expressed myoglobin (green) and arranged themselves in parallel (arrows in top row) before fusion. In a cross-section, newly formed myotube contained the human nuclei showed by Alu probe ISH and eosin staining (arrows in middle row, left panel). The gaps between the human cells (showed by the Alu probe ISH) were visible (arrow in middle row, right panel), indicating that fusion was still in process in the myotube. In some myotube sections, only human nuclei were detected (arrow in bottom row, left panel). They also expressed $\alpha$-actinin (green, arrow in bottom row, right panel). Images were from an experiment using the H1 line. (D) Myogenic differentiation in vivo. Human nuclei were identified either by the antiNuMA antibody (red) or by the probe against Alu repeats (purple). Most sections were counterstained with Hoechst 33342 (blue). Micrographs show striated myofibers containing human nuclei (purple or pink). Some myofibers contained nuclei of both human and mouse (blue) origins. The myofibers in the first row, left panel, show human nuclei detected by Alu probe (arrows in a and b). Myofibers were stained with eosin (a), and many of them clearly showed the striations (b). Regenerated myofibers have eccentric nuclei and express desmin, $\alpha$-actinin, troponin I, and dystrophin (arrows). In panels in the second row, $\alpha$-actinin immunostaining and Alu ISH were performed in sequence on the same sections. Dystrophin was expressed by hybrid myofibers containing one or two human nuclei (the right panel in the third row, arrows in a or b). A human nucleus located immediately outside the myofiber (arrowheads), a position typical for satellite cells. See Figure 4 for detailed analyses of satellite cells. Images were selected from experiments using both the $\mathrm{H} 1$ and the SH39 lines. Scale bars $=25 \mu \mathrm{m}$.

To examine myogenic potential of hES cells in vivo, an animal model is essential. We initially transplanted hES cell-derived precursors to NOD-SCID mice in which muscle tissue had been preconditioned with the degenerative agent, cardiotoxin $[7,19]$. This procedure resulted in the incorporation of a modest number of transplanted cells into the host myofibers $(7.65 \% \pm 2.07 \%)$ (Figure 1). Pathological examination following cardiotoxin injection into the mouse TA muscles revealed that shortly after the injury, muscle repair from host myogenic cells proceeds rapidly (Figure 3A). As proliferation of host myogenic cells may prevent the incorporation of transplanted cells, we irradi- ated the muscle after the cardiotoxin treatment. As shown in Figures 1 and 3A, irradiation at 25 Gy blocked muscle repair from endogenous cells to a significant degree and led to an improved incorporation of human cells into the host myofibers $(28.65 \% \pm 13.69 \%, P<0.01)$ (Figure 1). Irradiation at $18 \mathrm{~Gy}$ had a similar effect. The dose of 50 Gy, however, showed incorporation of transplanted cells to a lesser extent than the previous doses (data not shown). A time-course analysis was performed, in which cells were transplanted into preconditioned TA muscles 0,24 , and 48 $\mathrm{h}$ after irradiation. As shown in Table 1, transplantation at both 24 and $48 \mathrm{~h}$ led to a greater incorporation of hES cell- 


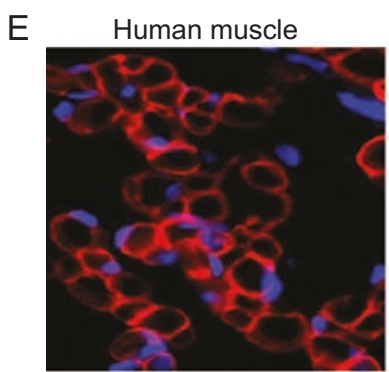

A transplanted site
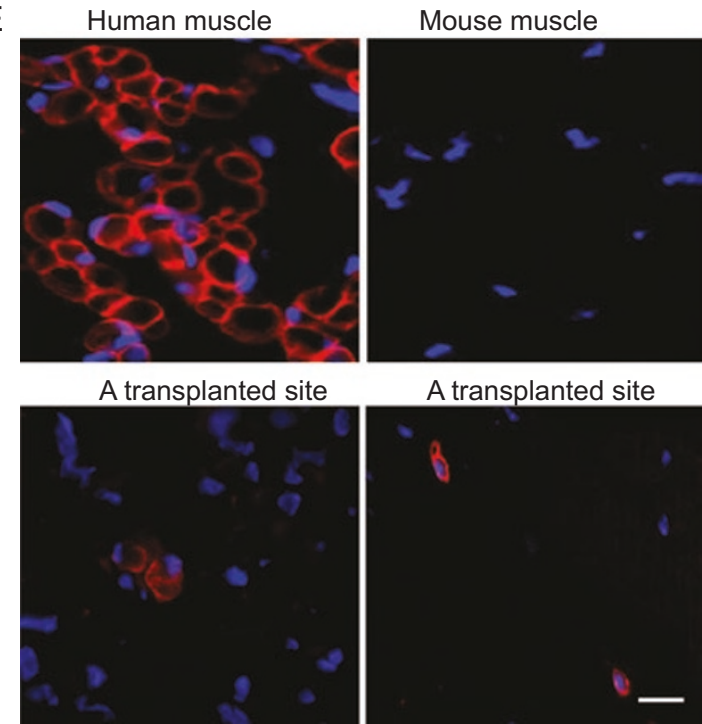

A transplanted site

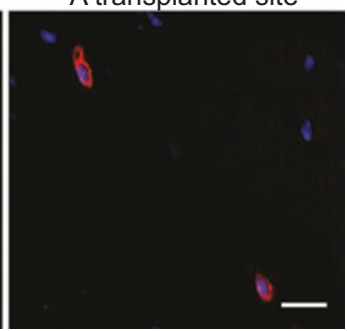

Figure 3 (E) Detection of dystrophin of human origin. The humanspecific anti-dystrophin antibody reacted to the human muscles but not to the mouse muscle. The antibody detected human dystrophin expression in the cells in transplantation sites. The H1 line was used in this experiment. Scale bar $=50 \mu \mathrm{m}$.

derived cells into the TA muscle. As transplanted cells do not migrate freely among myofibers [20,21], it is important that the cardiotoxin and cells are injected into the same site in order to achieve maximal incorporation. The mechanism by which irradiation increases the incorporation efficiency of myogenic precursors is not clear. Since irradiation eliminates preferentially proliferating cells, we assume that it may inhibit endogenous muscle precursors to proliferate and to incorporate into the muscle, although we cannot exclude the possibility that irradiation may also damage the stem cell niche for regeneration. As shown by data presented in this report, the model provides an inductive environment very similar to that in normal development. The myogenic process that occurs during embryogenesis is recapitulated in detail (see below).

During embryogenesis, post-mitotic mononucleated myoblasts begin to express muscle-specific structural proteins shortly after their birth and assemble themselves into striated myofibrils. The myoblasts fuse together to form myotubes and the myotubes mature to become myofibers. hES cell-derived precursors, in an adult environment, followed this sequence in myogenic differentiation. In muscle tissues dissected 2-16 weeks after transplantation, many mononucleated human cells were identified either by a probe hybridizing to primate-specific Alu repeats or by an antibody to human-specific NuMA. Some of these transplanted cells became elongated, expressed c-Met, desmin, MHC, $\alpha$-actinin, and displayed striated myofibrils (Figure 3B). Only a few MyoD- or Myf5-positive cells were detected, suggesting that most myogenic cells have withdrawn from the mitotic cycle and become further differentiated [22].

In the next step of the sequence, some elongated mononucleated cells arranged themselves in parallel (Figure 3C) and fused to form myotubes (Figure 3C). As part of the fusion process, the contiguous membranes of individual myoblasts dissolved, and the nuclei came into the center of the newly formed myotube (Figure 3C). Although only few sections of myotubes contained only human nuclei (Figure 3C), most of the human myoblasts fused with host myoblasts to form hybrid myotubes (Figure 3C and 3D). In the next stage, centrally located nuclei of myotubes moved to eccentric positions, indicating that the myotubes had matured to become myofibers (Figure 3D). Many regenerated myofibers, with human nuclei in various proportions, displayed striated myofibrils and expressed desmin, $\alpha$-actinin, troponin I, dystrophin (Figure 3D), and MHC (Figure $3 \mathrm{~B}$ ). Immunocytochemical analysis of tissue sections with an antibody-recognizing human-specific dystrophin confirmed that transplanted cells were expressing human dystrophin (Figure 3E).

In healthy, mature muscle, a satellite cell pool is maintained [23]. These cells are located next to the muscle fiber and under the basal lamina [1]. Depending on their state, satellite cells may express Pax7, Myf5, NCAM, or M-cadherin [18, 24, 25]. Immunochemical analyses of muscle tissue 2-16 weeks after transplantation revealed the presence of many human-originated satellite cells existing adjacent to myofibers (Figure 3D). To identify the position of hES cell-derived satellite cells, mirror images were collected from the paired sections after labeling with antibodies against laminin, NuMA, and M-cadherin. As shown in Figure 4A, NuMA- and M-cadherin-doublepositive cells were located inside myofibers, some were immediately underneath the lamina. Mononucleated human cells expressing satellite cell markers such as Myf5, NCAM, and M-cadherin (Figure 4B), as well as Pax 7 (data not shown), were also detected in the extracellular space. They may represent a subpopulation of satellite cells undergoing differentiation and migration. These results demonstrate that hES cell-derived precursor cells can give rise to satellite cells.

These findings indicate that hES cell-derived myogenic cells can contribute not only to muscle regeneration but also to replenishment of the satellite cell pool, and thus may provide a permanent source of precursor cells. The c-Met-positive mononucleated cells (Figures 2 and 3B) may be myogenic stem cells [17] generated from hES cells, 
which give rise subsequently to myoblasts and satellite cells. However, additional analysis is required to define these cells.

Transplantation of undifferentiated hES cells can generate teratomas [14]. It is important that the tumorgenerating potential of hES cells is eliminated through differentiation. We examined all the mice that received transplantation of hES cell-derived precursors for tumor formation. A total of 22 mice with 41 transplantation sites were evaluated and gross morphological and histological examination was carried out. Integration of hES derivatives into the muscle tissue was confirmed by ISH using the Alu probe for each transplantation site. Of the 41 sites examined, which ranged from 14 to 128 days posttransplantation, we detected no evidence of tumorigenesis (Table 3).
Table 3 Teratoma formation was not detected after transplantation

\begin{tabular}{lcccc}
\hline $\begin{array}{l}\text { hES cell } \\
\text { line }\end{array}$ & $\begin{array}{l}\text { Days after } \\
\text { transplantation }\end{array}$ & $\begin{array}{l}\text { Number of } \\
\text { transplantation } \\
\text { sites }\end{array}$ & Alu ISH & Teratoma \\
& \multicolumn{5}{c}{${ }^{* *}$} \\
\hline H1 & 14 & 5 & + & - \\
H1 & 28 & 3 & + & - \\
H1 & 33 & 1 & + & - \\
H1 & 108 & 4 & + & - \\
H1 & 122 & 2 & + & - \\
h39 & 14 & 16 & + & - \\
h39 & 24 & 2 & + & - \\
h39 & 45 & 4 & + & - \\
h39 & 56 & 2 & + & - \\
h39 & 128 & 2 & + & - \\
\hline
\end{tabular}

${ }^{*}$ Integration of hES derivatives was confirmed by Alu ISH.

** Teratoma formation was not observed by both the gross morphological and the histological analyses.
A

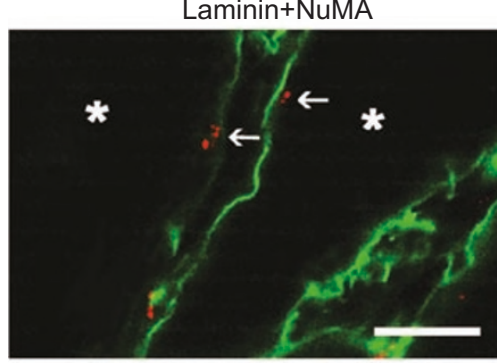

B

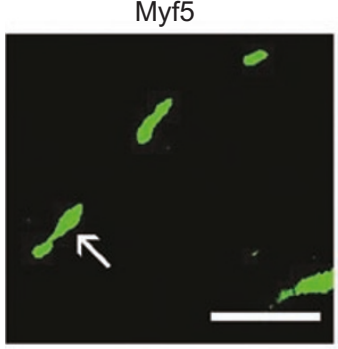

NCAM

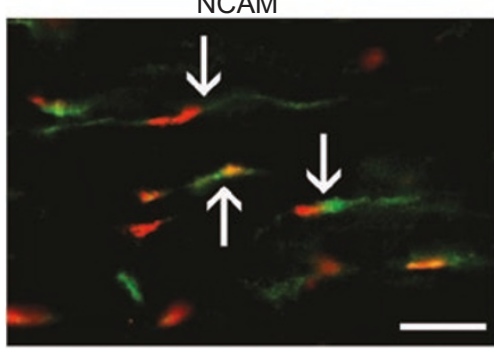

M-cad+NuMA

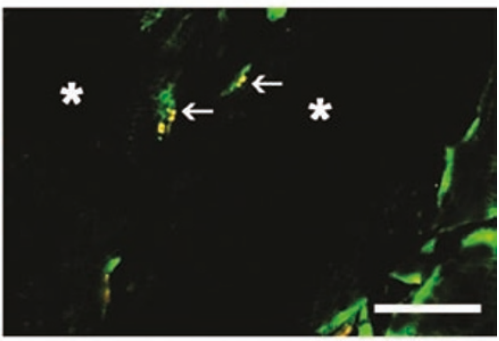

NuMA
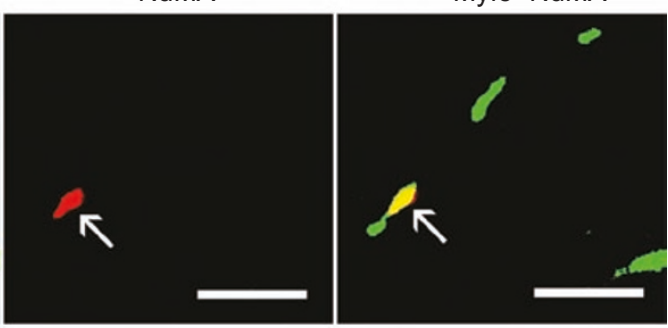

M-cadherin

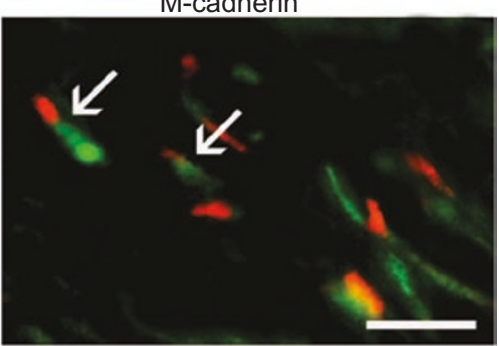

Figure 4 (A) hES cell-derived myogenic cells that were located under the lamina and expressed satellite cell markers. Mirror images were collected from paired sections (see Materials and Methods). Sections were labeled with antibodies against human-specific NuMA plus either M-cadherin or laminin. Cells located inside myofibers (marked by *) outlined by laminin expressed NuMA and satellite cell marker, M-Cad (arrows). The experiment was performed using the H1 line. Scale bars $=25 \mu \mathrm{m}$. (B) Satellite cells of human origin (arrows) expressed Myf5, NCAM, and M-cadherin (green). Human nuclei were identified by the anti-NuMA antibody (red). The SH39 line was used in this experiment. Scale bars $=25 \mu \mathrm{m}$. 
Two hES cell lines, H1 and SH39, were examined for their myogenic potential. Both cell lines were incorporated into the host tissue (Table 3 ). In a quantitative analysis, the SH39 line had higher incorporation efficiency than that of the H1 line (the percentage of hybrid myofibers out of the total myofibers at the transplantation site was approximately $28 \%$ for the SH39 line and $13 \%$ for the H1 line, data not shown). Immunohistochemical analyses showed that cells differentiated from both lines expressed muscle cell markers (Figures 3 and 4, and data not shown). These findings indicate that both lines are capable of myogenic differentiation, but have different efficiencies.

\section{Discussion}

In this report, we provide evidence that $\mathrm{hES}$ cell-derived precursors can incorporate into the host muscle efficiently and become part of regenerating muscle fibers. These precursor cells give rise to myocytes, myotubes, and myofibers, as well as satellite cells.

In most myopathies, a poor clinical outcome is ultimately due to a failure of satellite cells to maintain muscle regeneration. Restoration of the regeneration potential of the damaged muscle is important for maintaining a stable muscle function over a long term. hES cell-derived precursors give rise to both myocytes and satellite cells, providing an advantage in this regard. Another advantage for using $\mathrm{hES}$ cell-derived precursors for treating myogenic disorder is that patient's own somatic cells can be used to derive $\mathrm{hES}$ cells that are immune compatible to the patient through therapeutic cloning [16, 26-28].

Several culture media were used in this study to prompt myogenic differentiation of hES cells. Expression of myogenic determinants, such as myo D and myf5, indicated that a substantial proportion of the hES cells in culture were committed to muscle differentiation pathway. However, the differentiation was far from complete under the culture conditions tested. Myocytes did not fuse to form myotubes and to mature into myofibers in vitro. However, when transplanted, these cells went through a complete process of myogenesis to give rise to both myotubes and myofibers. These data suggest that the in vivo environment has provided necessary signals, which are absent in the culture. Since hES cell derivatives are detected to express myogenic markers both before and after incorporation into myotubes, we assume that the inductive signals exist both outside and inside myotubes. The fusion of hES derivatives into regenerating myotubes and myofibers may induce myogenic differentiation. After transplantation, only a small percentage of hES cell derivatives express human-specific dystrophin. The reason for lacking of dystrophin expression in majority hES cell derivatives is not clear at present.

Myogenesis is a multi-step process. Differentiation of hES cells may provide a useful system to dissect signals required for the process.

\section{Acknowledgments}

We are grateful to Mrs Youmin Zhu for her excellent technical support and to Dr Jianxin Chu for his assistance in ISH and animal model analysis. This work was supported by grants from Development Plan of the State Key Fundamental Research of China (Nos. 001CB509903 and 001CB509904), National High Technology Research and Development Project of China (Nos. 2001AA216121 and 2004AA205010), National Natural Science Foundation of China (No. 30040003), Shanghai Science and Technology Development Foundation (Nos. 99DJ14002, 00DJ14033, 01DJ14003, and 03DJ14017), Chinese Academy of Science (No. KSCX-2-3-08), and Shanghai Municipal Education Commission and Shanghai Second Medical University.

\section{References}

1 Mauro A. Satellite cell of skeletal muscle fibers. J Biophys Biochem Cytol 1961; 9:493-495.

2 Jejurikar SS, Kuzon Jr WM. Satellite cell depletion in degenerative skeletal muscle. Apoptosis 2003; 8:573-578.

3 Mendell JR, Kissel JT, Amato AA, et al. Myoblast transfer in the treatment of Duchenne's muscular dystrophy. N Engl J Med 1995; 333:832-838.

4 Webster C, Blau HM. Accelerated age-related decline in replicative life-span of Duchenne muscular dystrophy myoblasts: implications for cell and gene therapy. Somat Cell Mol Genet 1990; 16:557-565.

5 Beauchamp JR, Morgan JE, Pagel CN, Partridge TA. Dynamics of myoblast transplantation reveal a discrete minority of precursors with stem cell-like properties as the myogenic source. J Cell Biol 1999; 144:1113-1122.

6 De Angelis L, Berghella L, Coletta M, et al. Skeletal myogenic progenitors originating from embryonic dorsal aorta coexpress endothelial and myogenic markers and contribute to postnatal muscle growth and regeneration. J Cell Biol 1999; 147:869878.

7 Ferrari G, Cusella-De Angelis G, Coletta M, et al. Muscle regeneration by bone marrow-derived myogenic progenitors. Science 1998; 279:1528-1530.

8 Camargo FD, Green R, Capetanaki Y, Jackson KA, Goodell MA. Single hematopoietic stem cells generate skeletal muscle through myeloid intermediates. Nat Med 2003; 9:1520-1527.

9 Gussoni E, Soneoka Y, Strickland CD, et al. Dystrophin expression in the mdx mouse restored by stem cell transplantation. Nature 1999; 401:390-394.

10 Jackson KA, Mi T, Goodell MA. Hematopoietic potential of stem cells isolated from murine skeletal muscle. Proc Natl Acad Sci USA 1999; 96:14482-14486.

11 Bachrach E, Li S, Perez AL, et al. Systemic delivery of human 
microdystrophin to regenerating mouse dystrophic muscle by muscle progenitor cells. Proc Natl Acad Sci USA 2004; 101:3581-3586.

12 Torrente Y, Belicchi M, Sampaolesi M, et al. Human circulating $\mathrm{AC} 133(+)$ stem cells restore dystrophin expression and ameliorate function in dystrophic skeletal muscle. J Clin Invest 2004; 114:182-195.

13 De Bari C, Dell'Accio F, Vandenabeele F, et al. Skeletal muscle repair by adult human mesenchymal stem cells from synovial membrane. J Cell Biol 2003; 160:909-918.

14 Thomson JA, Itskovitz-Eldor J, Shapiro SS, et al. Embryonic stem cell lines derived from blastocysts. Science 1998; 282:11451147.

15 Itskovitz-Eldor J, Schuldiner M, Karsenti D, et al. Differentiation of hES cells into EBs compromising the three embryonic germ layers. Mol Med 2000; 6:88-95.

16 Chen Y, He ZX, Liu A, et al. Embryonic stem cells generated by nuclear transfer of human somatic nuclei into rabbit oocytes. Cell Res 2003; 13:251-263.

17 Miller JB, Schaefer L, Dominov JA. Seeking muscle stem cells. Curr Top Dev Biol 1999; 43:191-219.

18 Cornelison DD, Wold BJ. Single-cell analysis of regulatory gene expression in quiescent and activated mouse skeletal muscle satellite cells. Dev Biol 1997; 191:270-283.

19 Fukada S, Miyagoe-Suzuki Y, Tsukihara H, et al. Muscle regeneration by reconstitution with bone marrow or fetal liver cells from green fluorescent protein-gene transgenic mice. J Cell Sci 2002; 115:1285-1293.
20 El Fahime E, Torrente Y, Caron NJ, Bresolin MD, Tremblay JP. In vivo migration of transplanted myoblasts requires matrix metalloproteinase activity. Exp Cell Res 2000; 258:279-287.

21 Torrente Y, El Fahime E, Caron NJ, Bresolin N, Tremblay JP. Intramuscular migration of myoblasts transplanted after muscle pretreatment with metalloproteinases. Cell Transplant 2000; 9:539-549.

22 Smith II CK, Janney MJ, Allen RE. Temporal expression of myogenic regulatory genes during activation, proliferation, and differentiation of rat skeletal muscle satellite cells. J Cell Physiol 1994; 159:379-385.

23 Snow MH. The effects of aging on satellite cells in skeletal muscles of mice and rats. Cell Tissue Res 1977; 185:399-408.

24 Seale P, Sabourin LA, Girgis-Gabardo A, et al. Pax7 is required for the specification of myogenic satellite cells. Cell 2000; 102:777-786.

25 Bleisch W, Scharff C, Nottebohm F. Neural cell adhesion molecule (N-CAM) is elevated in adult avian slow muscle fibers with multiple terminals. Proc Natl Acad Sci USA 1989; 86:64036407.

26 Solter D, Gearhart J. Putting stem cells to work. Science 1999; 283:1468-1470.

27 Lanza RP, Cibelli JB, West MD. Human therapeutic cloning. Nat Med 1999; 5:975-977.

28 Colman A, Kind A. Therapeutic cloning: concepts and practicalities. Trends Biotechnol 2000; 18:192-196.

Edited by Duanqing Pei 